\title{
PENGARUH TINGKAT KETERGANTUNGAN DAERAH, TEMUAN AUDIT BPK, JUMLAH SATUAN KERJA PERANGKAT DAERAH, DAN UKURAN LEGISLATIF TERHADAP TINGKAT PENGUNGKAPAN LAPORAN KEUANGAN PEMERINTAH DAERAH
}

\author{
M Ridwan', M Rizal Yahya"2 \\ ${ }^{1,2}$ Program Studi Akuntansi Fakultas Ekonomi Universitas Syiah Kuala \\ e-mail: mridwann2396@gmail.com ${ }^{1}$,rizal_yahya@unsyiah.ac.id ${ }^{* 2}$ \\ * Corresponding Author
}

\begin{abstract}
This research aims to determine the influence of intergovernmental revenue, audit findings of the BPK, functional differentiation and legislative size to the level of disclosure of Local Government Financial Statements (LKPD) district/city in Aceh in 2015-2017. The population in this research is the Regency/city government in Aceh. The sample techniques in this study used the census method with 69 samples of the BPK-RI test Results Report of 20152017. The independent variables examined in this study were intergovernmental revenue, the BPK audit findings, the number of SKPD, and the legislative measures. While the dependent variable is the level of disclosure of Local Government Financial Statements (LKPD). The type of data used in this study is secondary data. The analyses used in this study were multiple linear regression. Subsequent data is processed by using the SPSS test tool. The results of the study showed the intergovernmental revenue, BPK audit findings, the number of SKPD, and the size of the legislature jointly impacted the level of LKPD disclosure. A partial intergovernmental revenue and the number of SKPD have a positive effect on LKPD disclosure rates, whereas BPK audit findings and legislative measures negatively affect $L K P D$ disclosure rates.
\end{abstract}

Keywords: audit findings, functional differentiation, intergovernmental revenue, legislative size, level of disclosure

\section{Pendahuluan}

Pada era akuntansi modern praktek akutansi sektor publik (ASP) yang dilaksanakan oleh lembaga pemerintahan menerima atensi lebih daripada yang telah lalu dari pelbagai kalangan. Masyarakat menuntut adanya transparan dan pemerintah yang akuntabel terkait kegiatan lembaga pemerintahan dididalam satu periode tertentu (Khasanah \& Rahardjo, 2014). Sehingga dengan tingginya tuntutan masyarakat mengakibatkan perlunya penerapan tata kelola perihal publik yang baik (good governance).

Salah satu bentuk untuk menciptakan good governance (GG) didalam dikelolanya keuangan Pemerintah Daerah (pemda) dan pemerintahan induk yakni kewajiban untuk menyampaikan pertanggungjawaban didalam format yang sesuai SAP (Standar Akutansi Pemerintahan). Laporan Keuangan (LK) pemda minimal berisi Laporan Realisasi Anggaran (LRA), Laporan Posisi Keuangan, LAK, dan Catatan atas Laporan Keuangan (CaLK) (Setyaningrum \& Syafitri, 2012). Sebuah Standar Akutansi dibutuhkan sebagai pedoman didalam penyusunan LK. Oleh karena itu, tahun 2010 pemerintahan menerbitkan PP terbaru terkait Standar Akutansi Pemerintahan yakni PP No. 71 Tahun 2010 mengenai Standar Akutansi Pemerintahan (SAP).

Berlandaskan SAP, Peraturan Pemerintahan (PP), dan juga Undang-Undang (UU) yang berlaku maka LK yang disusun pemda akan sama seperti peraturan yang sesuai. Namun, apakah pemda telah menyajikan informasi yang lengkap didalam LK Pemda. Beberapa hasil studi sebelumnya terkait tingkat penyajian wajib didalam LK Pemda di Indonesia kepada SAP masih minim. Studi Lesmana \& Suhardjanto (2010) yakni sebesar 22\%, Hilmi \& Martani (2012) 44,56\%, Setyaningrum \& Syafitri (2012) sebesar 52,09\% dan Pandansari (2016) 58\%. 
Studi ini memperlihatkan bahwasanya pemda belum sepenuhnya menyajikan item penyajian wajib didalam LK.

Studi sebelumnya memperlihatkan tingkat penyajian yang masih tergolong minim menyebabkan peneliti berminat untuk meneliti lebih lanjut mengenai faktor yang memengaruhi tingkat penyajian wajib LK Pemda. Feriyanti, Hermanto, \& Suransi (2015) berpendapat bahwasanya Tingkat Penyajian LK Pemda dipengaruhi oleh faktor Tingkat Ketergantungan Daerah. Pemerintahan induk dan provinsi akan meminta penyajian penggunaan anggaran sebagai bentuk pengawasan kepada kinerja pemda terkait dana yang dipergunakan untuk meningkatkan kesejahteraan masyarakat. Semakin besar tingkat ketergantungan daerah kepada pemerintahan induk ataupun provinsii maka dapat menyebabkan semakin besarnya tingkat penyajian yang harus diperlakukan oleh pemda. Pertanggung jawaban pemda kepada penggunaan biaya yang bersumber dari pemerintahan induk ataupunpun provinsi ialah sebagai salah suatu bentuk upaya didalam menjalankan prinsip transparansi dan akuntabel, guna meningkatkan kepercayaan publik kepada pemda bahwasanya tidak ada dana yang disalahgunakan.

Terdapat dua studi yang terkait Tingkat

Ketergantungan Daerah. Ratnasari (2016) mengemukakan bahwasanya tingkat ketergantungan berpengaruh kepada tingkat penyajian LK Pemda. Studi berbeda ditunjukkan oleh Syafitri dan Setyaningrum (2012) yakni tingkat ketergantungan daerah tidak memberi pengaruh kepada tingkat penyajian LK Pemda.

Ratnasari (2016) menyatakan bahwasanya faktor lain yang memengaruhi tingkat penyajian LK Pemda yakni hasil dari temuan audit Badan Pemeriksa Keuangan (BPK). Adanya temuan audit disebabkan karena indikasi ketidakpatuhan kepada UU dari pemeriksaan LK Pemda. Pemda akan diminta untuk menindaklanjuti rekomendasi BPK terkait temuan audit sebagai bentuk tingkat penyajian pemda kepada LK. Hal ini ialah bentuk pelayanan pemda terkait pelaksanaan kegiatan pemerintah kepada masyarakat. Banyaknya temuan audit BPK akan berdampak kepada tingkat penyajian informasi yang harus disajikan ataupun dijelaskan pemda terkait pengelolaan keuangan daerah, sehingga meningkatkan kepercayaan masyarakat kepada pemerintahan.

Terkait jumlah temuan audit BPK terdapat dua studi yang berbeda. Studi Martani \& Liestiani (2010) menyajikan bahwasanya temuan audit BPK berpengaruh kepada tingkat pengungakapan LK Pemda. Sedangkan Hendriyani \& Tahar (2015) yang menyajikan bahwasanya temuan audit BPK tidak memberi pengaruh kepada tingkat penyajian LK Pemda.

Ernawati (2016) menyajikan bahwasanya Jumlah Satuan Kerja Perangkat Daerah (SKPD) dapat memengaruhi tingkat penyajian LK Pemda. SKPD menggambarkan jumlah kegiatan ataupun prioritaspemda didalam membangun daerahnya, SKPD berkewajiban mencatat aktifitas keuangan yang dilakukan pada sekitar pemda. Kaitannya ialah apabila sebuah daerah semakin banyak mempunyai SKPD mengakibatkan semakin rumitnya sebuah pemerintah dan berpengaruh kepada informasi - informasi yang wajib disajikan kepada masyarakat didalam LKPD juga semakin banyak, hal ini sebagai bentuk mengurangi penyimpangan dan penyajian informasi terkait pengelolaan keuangan oleh SKPD, dan juga menciptakan pemerintah yang baik.

Terdapat perbedaan studi terkait pengaruh jumlah SKPD kepada tingkat penyajian LK Pemda. Ernawati (2016) menyajikan bahwasanya terdapat pengaruh dari jumlah SKPD kepada tingkat penyajian LK Pemda. Sedangkan Simbolon \& Kurniawan (2018) mengatakan bahwasanya ketiadaan pengaruh jumlah SKPD kepada penyajian LK Pemda.

Alasan lain yang memengaruhi tingkat penyajian LK Pemda menurut Rahayu \& Mardiana (2016) yakni ukuran legislatif, didalam hal ini ditunjukkan oleh jumlah anggota Dewan Perwakilan RakyatDaerah yang akan memberi pressure kepada pemerintahan untuk penyajian laporan keungan. Hal ini sesuai dengan salah satu fungsi dari DPRD yakni fungsi pengawasan yang bertugas mengendalikan lajunya pemerintah supaya sesuai seperti apa yang di sarankan masyarakat dan memantau dilaksanakannya pelaporan dan penyajian informasi keuangan pemda agar bersifat akuntabel dan transparan.

Terdapat studi berbeda terkait ukuran legislatif kepada tingkat penyajian LK Pemda. Studi Setyaningrum \& Syafitri (2012) menyajikan bahwasanya ukuran legislatif berpengaruh kepada tingkat penyajian LK Pemda. Menurut Khasanah \& 
Rahardjo (2014) yang menyajikan bahwasanya tidak adanya pengaruh ukuran legislatif kepada tingkat penyajian LK Pemda.

Berdasarkan situasi itu peneliti berminat untuk menganalisa faktor yang memengaruhi penyajian wajib LKPD kepada SAP yang berlaku. Studi ini memakai penyajian wajib (mandatory disclosure) dikarenakan peneliti akan membandingkan antar penyajian yang ada didalam LKPD dengan yang seharusnya disajikan menurut Standar Akutansi pemerintah.

\section{Kajian Teoritis dan Pengembangan Hipotesis}

\section{Pengungkapan Laporan Keuangan Pemerintah Daerah}

Kata penyajian yang berarti tidak menutupi bila dikaitkan dengan LK berarti sebuah LK yang semestinya menyajikan informasi dan juga penjelasan yang lengkap mengenai kegiatan sebuah unit upaya tertentu. Adapun maksud penyajian secara umum ialah untuk menyajikan informasi yang dianggap penting guna melayani pelbagai pihak yang mempunyai keperluan berbeda-beda kepada LK tersebut (Ghozali \& Chariri, 2007:38). Sedangkan menurut Setyaningrum \& Syafitri (2012), ada empat keperluan dari pelaporan laporan keungan, yakni akuntabel, manajemen, transparansi, keseimbangan antar generasi.

Salah satu unsur utama sebuah LK pemerintahan ialah CaLK. Didalam PP No. 71 Tahun 2010 telah disebutkan CaLK mencakup penjelasan naratif angka yang tertera dididalam LRA, Laporan Perubahan SAL, Laporan Operasional, Laporan Perubahan Ekuitas (LPE), Laporan Posisi Keuangan, dan LAK. CaLK mengandung informasi terkait kebijakan akutansi yang digunakan sebuah lembaga juga informasi yang harus disajikan berdasarkan SAP. Berdasarkan PP No. 71 Tahun 2010 Lampiran I, CaLK menyajikan informasi Lembaga Pelaporan dan Lembaga Akutansi, informasi kebijakan fiskal, ikhtisar pencapaian target keuangan, informasi mengenai penyajian LK dan kebijakan akutansi yang digunakan, penjelasan terkait pos-pos pada muka LK, informasi yang diharuskan SAP yang tidak disajikan, informasi lain untuk penyajian yang wajar.

Motode sistem scoring jenis penyajian wajib dilakukan didalam studi ini. Maksud dari sistem scorring ialah untuk menyusun daftar daftar periksa penyajian wajib berdasarkan SAP No. 71 tahun 2010. Seperti yang telah dilakukan oleh Lesmana \& Suhardjanto (2010) dan Setyaningrum \& Syafitri (2012).

\section{Tingkat Ketergantungan Daerah}

Menurut Mustikarini \& Fitriasari (2012) tingkat ketergantungan pemda kepada pemerintahan induk ataupun provinsi dinyatakan dengan besarnya Dana Alokasi Umum (DAU) dibandingkan dengan total pendapatan.

Khasanah \& Rahardjo (2014) memaparkan bahwasanya tingkat ketergantungan daerah ialah jenis pendanaan untuk area yang berasal dari pemerintahan induk ataupun provinsi. Pemerintahan induk ataupun provinsi tentunya menuntut pengunngkapan detail kepada pemda terkait pemakaian anggaran tersebut. Penyajian yang harus dilakukan pemda akan bertambah banyak apabila tingkat ketergantungan daerah semakin besar pula. Pertanggungjawaban atas dana yang di terima oleh pemda tersebut ialah bentuk upaya kesadaran dari pemda untuk memenuhi tanggung jawabnya secara transparan dan akuntable kepada penggunaan anggaran juga didalam bentuk menjaga kepercayaan publik (masyarakat) kepada pemerintahan.

Menurut studi Feriyanti, Hermanto, \& Suransi (2015) menemukan bahwasanya terdapat hubungan signifikan antar tingkat ketergantungan kepada tingkat penyajian LK Pemda.

\section{Temuan Audit BPK}

Temuan audit menurut Hendriyani \& Tahar (2015) ialah kasus-kasus pada LK yang di temukan oleh BPK didalam bentuk ketidakcocokan dengan implementasi laporan dan identifikasi sebagai pelanggaran. Temuan audit dapat memperlihatkan ketidakpatuhan dengan kriteria audit ataupun mempunyai ruang untuk perbaikan.

Menurut Khasanah \& Rahardjo (2014) temuan audit ialah kasus-kasus yang di indentifikasi oleh BPK kepada LK Pemda atas pelanggaran yang dilakukan oleh wilayah kepada ketentuan pengendalian internal ataupun kepada hukum yang berlaku. Pada studi Martani \& Liestiani (2010) memperlihatkan bahwasanya terdapat pengaruh yang signifikan temuan audit BPK kepada 
tingkat penyajian LK pemda.

\section{Jumlah SKPD}

Menurut Permendagri No. 13 Tahun 2006 mengenai Pedoman Pengelolaan Keuangan Daerah, SKPD ialah perangkat daerah sebagai pengguna anggaran / pengguna barang. Didalam struktur Pemerintahan Indonesia, divisi departemen fungsional didefinisikan sebagai SKPD.

SKPD ialah sebuah lembaga yang diwajibkan untuk melaksanakan pembukuan kegiatan dilaksanakan ataupun yang berlangsung di pemda Setyaningrum \& Syafitri (2012). Menurut Hilmi \& Martani (2012) semakin besar jumlah SKPD yang dimiliki oleh pemda, semakin rumit pemerintahan, semakin tinggi tingkat penyajian yang harus dilakukan oleh pemda. Studi Khasanah \& Rahardjo (2014) memperlihatkan bahwasanya adanya pengaruh signifikan antar variabel jumlah SKPD kepada tingkat penyajian LK Pemda.

\section{Ukuran Legislatif}

Menurut UU No. 32 Tahun 2004 Lembaga legislatif ataupun Dewan Perwakilan Rakyat Daerah ataupun yang dikenal DPRD ialah lembaga perwakilan rakyat daerah dan berperan juga didalam pelaksanaan pemerintah. Sedangkan menurut Winarna \& Murni (2007) DPRD ialah lembaga yang mempunyai peran penting didalam mengontrol kebijakan keuangan sebuah daerah.

Menurut Setyaningrum \& Syafitri (2012) legislatif atau DPRD ialah lembaga yang mewakili masyarakat dan mempunyai fungsi untuk mengawasi pemerintahan agar selalu sesuai untuk mewakilkan aspirasi masyarakat dan mengevaluasi pelaksanaan kegiatan pemda dan juga mengawasi pelaporan terkait informasi keuangan pemda agar tercipta pemerintah yang transparan.

Pada Studi Setyaningrum \& Syafitri (2012) memaparkan bahwasanya adanya pengaruh signifikan antar pengaruh ukuran legislatif kepada tingkat penyajian LKPD.

\section{Hipotesis}

Hipotesis pada studi ini ialah sebagai berikut:

$\mathrm{H}_{1}$ : Tingkat Ketergantungan, Temuan Audit BPK, dan Kompleksitas Pemerintahan yang diproksikan dengan jumlah SKPD dan ukuran legislatif berpengaruh secara simultan terhadap Tingkat Pengungkapan Laporan Keuangan Pemerintah Daerah Kabupaten/Kota di Aceh Tahun 2015-2017.

$\mathrm{H}_{2}$ : Tingkat Ketergantungan Daerah berpengaruh terhadap Tingkat Pengungkapan LKPD Kabupaten/Kota di Aceh Tahun 2015-2017.

H3: Jumlah Temuan Audit BPK berpengaruh terhadap Tingkat Pengungkapan LKPD Kabupaten/Kota di Aceh Tahun 2015-2017.

H4: Jumlah SKPD berpengaruh terhadap Tingkat Pengungkapan LKPD Kabupaten/Kota di Aceh Tahun 2015-2017.

H5: Ukuran Legislatif berpengaruh terhadap Tingkat Pengungkapan LKPD Kabupaten/Kota di Aceh Tahun 2015-2017.

\section{Metode Penelitian \\ Desain Penelitian}

Studi ini bertujuan untuk menguji hipotesis. Penelitian ini kuantitatif dimana tingkat intervensi dalam studi ini ialah minimal. Jenis investigasi pada studi ini menggunakan jenis studi kausal. Situasi studi ini adalah tidak diatur. Unit analisis studi adalah Kabupaten/Kota di Aceh, dan data yang digunakan merupakan data sekunder. Penelitian ini bersifat pooled data.

\section{Populasi dan Sampel Penelitian}

Populasi pada penelitian ini adalah seluruh kabupaten/kota di Aceh sebanyak 23 kabupaten/kota yang terdiri dari 18 kabupaten dan 5 kota dijadikan sebagai populasi penelitian. Adapun rentang waktu yang digunakan adalah tiga tahun yang di mulai dari tahun 2015 hingga 2017 dan memerlukan laporan keuangan yang telah diaudit oleh BPK, karena jumlah populasi yang dianggap kecil maka studi ini memakai metode sensus.

\section{Sumber dan Teknik Pengumpulan Data}

Studi ini berpedoman kepada data sekunder. Definisi data sekunder menurut Sekaran \& Bougie (2017:130) ialah data yang tidak perlu dikumpulkan lagi oleh peneliti dikarenakan data tersebut bisa diperoleh oleh peneliti dengan cara tidak langsung yakni melalu media perantara. Didalam studi ini yang dimaksudkan media perantar tersebut ialah LKPD yang telah diaudit oleh BPK RI yang diperoleh dari 
Induk Informasi dan Komunikasi (PIK) pada website (www.bpk.go.id). Teknik pengumpulan data yang digunakan berupa teknik dokumentasi dan permintaan informasi melalui website.

\section{Operasionalisasi Variabel}

Variabel Dependen

Menurut Sekaran \& Bougie (2017:77) variabel terikat yakni variabel yang menjadi pehatian dari sebuah studi. Didalam studi ini pengukur tingkat penyajian memakai sistem scoring yang memberikan skor dengan membuat daftar checklist penyajian yang telah diwajibkan oleh SAP. Penggunaan sistem scoring ini serupa dengan yang pernah dilaksanakan oleh Setyaningrum \& Syafitri (2012) dan Lesmana \& Suhardjanto (2010).

\section{Variabel Independen}

\section{Tingkat Ketergantungan Daerah}

Menurut Ara, Herwanti, \& Pituringsih (2016) tingkat ketergantungan pemda kabupaten ataupun kota kepada pemerintahan induk ataupun provinsi yang berbeda-beda diwujudkan didalam bentuk penerimaan Dana Alokasi Umum (DAU). Didalam studi Khasanah \& Rahardjo (2014) dan Ara, Herwanti, \& Pituringsih (2016) pengukuran variabel tingkat ketergantungan da erah memakai perbandingan antar realisasi DAU dibandingkan dengan total pendapatan.

\section{Temuan Audit BPK}

Menurut Khasanah \& Rahardjo (2014) temuan audit ialah pelanggaran yang di indentifikasi oleh BPK kepada LKPD atas pelanggaran yang dilaksanakan sebuah daerah kepada sebuah ketentuan pengendalian internal maupun kepada UU yang berlaku.

\section{Jumlah SKPD}

Didalam struktur pemerintahan Indonesia, pembagian departemen fungsional diartikan sebagai SKPD. Didalam studi Hilmi \& Martani (2012) dan Khasanah \& Rahardjo (2014) jumlah SKPD diukur dengan total seluruh SKPD yang terdapat didalam sebuah daerah.

\section{Ukuran Legislatif}

Digunakannya jumlah anggota DPRD didalam melihat ukuran legislatif telah banyak dilaksanakan pada studi sebelumnya seperti yang dilaksanakan oleh Gilligan \& Matsusaka (2001). Dalam studi yang dilaksanakan Setyaningrum \& Syafitri (2012) juga memakai jumlah anggota DPRD sebagai alat ukur ukuran legislatif.

\section{Metode Analisis Data}

Model ini akan menguji pengaruh tingkat ketergantungan daerah $\left(\mathrm{X}_{1}\right)$ temuan audit $\mathrm{BPK}\left(\mathrm{X}_{2}\right)$, jumlah SKPD (X3) dan ukuran legislatif (X4) kepada tingkat penyajian LKPD (Y). Persamaan regresi yang dilaksanakan ialah:

$$
Y=\alpha+\beta_{1} X_{1}+\beta_{2} X_{2}+\beta_{3} X_{3}+\beta_{4} X_{4}+e
$$

Dimana:

$\mathrm{Y} \quad=$ Tingkat Pengungkapan LKPD

$\alpha \quad=$ Konstanta

$\beta 1-\beta 4=$ Koefisien Regresi

$\mathrm{X} 1=$ Tingkat Ketergantungan Daerah

$\mathrm{X} 2=$ Temuan Audit BPK

$\mathrm{X} 3=$ Jumlah SKPD

$\mathrm{X} 4=$ Ukuran Legislatif

e $\quad=$ Error term, yaitu tingkat kesalahan dalam penelitian

\section{Hasil dan Pembahasan}

Deskripsi Data Penelitian

Tabel 1. Deskprisi data penelitian

\begin{tabular}{|l|r|r|r|r|r|}
\hline \multicolumn{1}{|c|}{ Variabel } & N & Min & Max & Mean & $\begin{array}{c}\text { Std. } \\
\text { Deviatio } \\
\mathrm{n}\end{array}$ \\
\hline $\begin{array}{l}\text { Tingkat } \\
\text { Pengungkapan }\end{array}$ & 69 & 37.74 & 60.38 & 46.95 & 4.739 \\
\hline $\begin{array}{l}\text { Tingkat } \\
\text { Ketergantungan }\end{array}$ & 69 & .33 & .64 & .46 & .056 \\
\hline $\begin{array}{l}\text { Jumlah Temuan } \\
\text { Audit }\end{array}$ & 69 & 7.00 & 24.00 & 15.10 & 4.066 \\
\hline $\begin{array}{l}\text { Jumlah SKPD } \\
\text { Jumlaah Anggota } \\
\text { DPRD }\end{array}$ & 69 & 20.00 & 45.00 & 28.47 & 7.636 \\
\hline Valid N (listwise) & 69 & & & & \\
\hline
\end{tabular}

Sumber: Data Sekunder (diolah) 2019 
Analisis Data dan Pengujian Hipotesis

Tabel 2. Analisis Regresi Linier Berganda

\begin{tabular}{|l|l|r|}
\hline \multicolumn{1}{|c|}{$\begin{array}{c}\text { Variabel } \\
\text { Independen }\end{array}$} & \multicolumn{1}{|c|}{$\begin{array}{c}\text { Prediksi } \\
\text { Tanda }\end{array}$} & \multicolumn{1}{c|}{$\begin{array}{c}\text { Koefisien } \\
\text { Regresi }\end{array}$} \\
\hline Constant & & 40,085 \\
\hline $\begin{array}{l}\text { Tingkat } \\
\text { ketergantingan }\end{array}$ & Positif & 27,467 \\
\hline Temuan Audit & Negatif & $-0,358$ \\
\hline Jumlah SKPD & Positif & 0,070 \\
\hline Ukuran Legislatif & Negatif & $-0,134$ \\
\hline $\begin{array}{l}\text { Variabel } \\
\text { Dependen }\end{array}$ & Tingkat Pengungkapan LKPD \\
\hline R Square & 0,299 \\
\hline
\end{tabular}

Sumber: Data Sekunder (diolah) 2019

Model analisa regresi pada studi ini ialah untuk mengetahui pengaruh dari tingkat ketergantungan daerah, Temuan audit, jumlah SKPD, dan ukuran legislatif kepada tingkat penyajian LKPD. Berikut ini pengolahan data dilaksanakan memakai software SPSS:

\section{$\mathrm{Y}=40,085+27,467 \mathrm{X}_{1}-0,358 \mathrm{X}_{2}+0,070 \mathrm{X3}_{3}-$ \\ $0,134 X 4$}

\section{Koefisien Determinasi}

Pengaruh tingkat ketergantungan daerah, Temuan audit, jumlah SKPD, dan ukuran legislatif kepada tingkat penyajian LKPD diketahui nilai $\mathrm{R}$ Square sebesar 0,299, artinya tingkat ketergantungan daerah, Temuan audit, jumlah SKPD, dan ukuran legislatif memberikan perubahan kepada tingkat penyajian LKPD sebesar $29,9 \%$.

\section{Pengujian Hipotesis}

\section{Uji Simultan}

Uji simultan digunakan untuk mengetahui kesesuaian model variabel (fit ataupun tidak fit) dengan kriteria, jika nilai signifikansi $<0,05(\alpha=5 \%)$, maka model regresi dapat dikatakan fit. Nilai koefisien regresi variabel tingkat ketergantungan daerah sebesar $\beta 1=27,467$, variabel temuan audit sebesar $\beta 2=-0,358$, variabel jumlah SKPD sebesar $\beta 3=0,070$, dan jumlah anggota legislatif sebesar $\beta 4=-0,134$. Nilai koefisien regresi masing-masing variabel tidak sama dengan nol ataupun satu $ß \neq 0$, yang berarti tingkat ketergantungan daerah, temuan audit, jumlah SKPD, dan ukuran legislatif secara bersama-sama berpengaruh kepada tingkat penyajian LKPD. Maka dapat disimpulkan bahwasanya model studi ini fit. Artinya variabel independen memengaruhi variabel dependen.

\section{Uji Parsial}

Berdasarkan Tabel Regresi dapat diketahui:

a) Nilai koefisien regresi variabel tingkat ketergantungan daerah $\beta 1=27,467$. Nilai koefisien regresi $\beta_{1} \neq 0$, memperlihatkan tingkat ketergantungan daerah berpengaruh kepada tingkat penyajian LKPD, hipotesis satu diterima.

b) Nilai koefisien regresi variabel temuan audit sebesar $\beta 2=-0,358$. Nilai koefisien regresi $\beta_{2} \neq 0$, memperlihatkan temuan audit berpengaruh kepada tingkat penyajian LKPD. Hipotesis dua bahwasanya temuan audit berpengaruh kepada tingkat penyajian LKPD diterima.

c) Nilai koefisien regresi variabel jumlah sebesar $\beta 3=0,070$. Nilai koefisien regresi $\beta_{2} \neq 0$, memperlihatkan jumlah SKPD berpengaruh kepada tingkat penyajian LKPD. Hipotesis tiga bahwasanya jumlah SKPD berpengaruh kepada tingkat penyajian LKPD diterima.

d) Nilai koefisien regresi variabel jumlah legislatif sebesar $\beta 4=-0,134$. Nilai koefisien regresi $\quad \beta 2 \neq 0, \quad$ memperlihatkan jumlah legislatif berpengaruh kepada tingkat penyajian LKPD. Hipotesis empat bahwasanya jumlah legislatif berpengaruh kepada tingkat penyajian LKPD diterima.

\section{Pembahasan}

Pengaruh Tingkat Ketergantungan Daerah, Temuan Audit BPK, Jumlah SKPD, Dan Ukuran Legislatif Secara Simultan Terhadap Tingkat Pengungkapan LKPD

Berdasarkan hasil pengujian statistik diketahui bahwa variabel bebas yaitu tingkat ketergantungan daerah, temuan audit BPK, jumlah SKPD, dan ukuran legislatif secara simultan mempengaruh tingkat pengungkapan LKPD. Hasil pengujian membuktikan bahwa keempat variabel bebas tersebut seluruhnya mempengaruhi tingkat pengungkapan LKPD. 


\section{Pengaruh Tingkat Ketergantungan Daerah Terhadap Tingkat Pengungkapan LKPD}

Secara parsial tingkat ketergantungan daerah berpengaruh kepada tingkat penyajian LKPD. Studi ini konsisten dengan studi sebelumnya yakni studi Feriyanti, Hermanto, \& Suransi (2015) menemukan bahwasanya terdapat hubungan signifikan antar tingkat ketergantungan kepada tingkat penyajian LKPD.

Menurut Mustikarini \& Fitriasari (2012) tingkat ketergantungan pemda kepada pemerintahan induk ataupun provinsi dinyatakan DAU bagi total pendapatan.

\section{Pengaruh Temuan Audit BPK terhadap Tingkat Pengungkapan LKPD}

Secara parsial jumlah temuan audit berpengaruh kepada tingkat penyajian LKPD. Studi ini tidak konsisten dengan studi yang dilaksanakan oleh Ratnasari (2016) terdapat pengaruh yang signifikan antar temuan audit BPK kepada tingkat penyajian LKPD. Pada studi Martani \& Liestiani (2010) memperlihatkan bahwasanya terdapat pengaruh yang signifikan temuan audit BPK kepada tingkat penyajian LK pemda.

\section{Pengaruh Jumlah SKPD terhadap Tingkat Pengungkapan LKPD}

Secara parsial jumlah SKPD berpengaruh kepada tingkat penyajian LKPD. Studi ini konsisten dengan studi yang dilaksanakan Khasanah \& Rahardjo (2014) memperlihatkan bahwasanya adanya pengaruh signifikan antar variabel jumlah SKPD kepada tingkat penyajian LKPD. Menurut Setyaningrum \& Syafitri (2012) didalam struktur pemerintah Indonesia, pembagian departemen fungsional diartikan sebagai SKPD.

\section{Pengaruh Ukuran Legislatif terhadapTingkat Pengungkapan LKPD}

Secara parsial ukuran legislatif berpengaruh kepada tingkat penyajian LKPD. Studi ini konsisten dengan studi Gilligan \& Matsusaka (2001) terdapat pengaruh signifikan antar variabel ukuran legislatif kepada tingkat penyajian LKPD. Menurut UU No. 32 Tahun 2004 Lembaga legislatif ataupun DPRD mempunyai fungsi legislasi, anggaran, dan pengawasan. Menurut Setyaningrum \& Syafitri (2012)
DPRD ialah lembaga yang mewakili masyarakat dan mempunyai fungsi untuk mengawasi dan mengevaluasi terkait beragam aktivitas pemda agar transparan.

\section{Kesimpulan, Keterbatasan dan Saran Kesimpulan}

Kesimpulan dari analisa dan pembahasan studi ini ialah:

1. Tingkat ketergantungan daerah, temuan audit, jumlah SKPD, dan ukuran legislatif secara bersama-sama berpengaruh signifikan kepada tingkat penyajian LKPD pada Kabupaten / Kota di Provinsi Aceh.

2. Tingkat ketergantungan berpengaruh kepada tingkat penyajian LKPD pada Kabupaten / Kota di Provinsi Aceh.

3. Jumlah temuan berpengaruh kepada tingkat penyajian LKPD pada Kabupaten / Kota di Provinsi Aceh.

4. Jumlah SKPD memengaruhi kepada tingkat penyajian LKPD pada Kabupaten / Kota di Provinsi Aceh.

5. Ukuran legislatif berpengaruh kepada tingkat penyajian LKPD pada Kabupaten / Kota di Provinsi Aceh.

\section{Keterbatasan}

Penelitian ini memiliki keterbatasan yaitu pada studi ini pada variabel studi yang diteliti, yakni hanaya variabel tingkat ketergantungan daerah, temuan audit, jumlah SKPD, ukuran legislatif, dan tingkat penyajian LKPD.

\section{Saran}

Berdsasarkan studi ini, maka saran dari studi ini ialah.

a. Kepada studi selanjutnya diharap dapat memperluas variabel studi, seperti variabel kemandirian dan ukuran pemda.

b. Untuk pemda Kab/Kota Provinsi Aceh tahu mengenai faktor-faktor yang memengaruhi tingkat penyajian LKPD.

\section{Daftar Pustaka}

Ara, S. C., Herwanti, T., \& Pituringsih, E. (2016). Pengaruh Karakteristik Pemda Dan Temuan Audit Bpk Terhadap Kinerja Pemda Kabupaten 
Di Pulau Sumba. JAFFA, 4(1), 1-17.

Ernawati, T. (2016). Pengaruh Ukuran Pemerintah Daerah, Jumlah Skpd, Umur Pemerintah Daerah Dan Temuan Audit Terhadap Tingkat Pengungkapan Laporan Keuangan Pemerintah Daerah (LKPD). IOSR Journal of Economics and Finance, 3(1), 56.

Feriyanti, M., Hermanto, \& Suransi, N. K. (2015). Determinan Kepatuhan Pada Ketentuan Pengungkapan Wajib Laporan Keuangan Pemerintah Daerah (Studi Pada Kabupaten/Kota Di Provinsi Nusa Tenggara Barat). Jurnal InFestasi, 11(2), 171-185.

Ghozali, I. (2013). Aplikasi Analisis Multivariate Dengan Program IBM SPSS 21 Update PLS Regresi. Semarang: Badan Penerbit UNDIP.

Ghozali, I., \& Chariri, A. (2007). Teori Akuntansi.Semarang: Badan Penerbit UNDIP.

Gilligan, T. W., \& Matsusaka, J. G. (2001). Fiscal Policy, Legislature Size, and Political Parties: Evidence from State and Local Governments in the First Half of the 20th Century. National Tax Journal, 54(1), 57-82.

Hendriyani, R., \& Tahar, A. (2015). Analisis FaktorFaktor Yang Memengaruhi Tingkat Pengungkapan Laporan Keuangan Pemerintah Provinsi Di Indonesia. Jurnal Bisnis Dan Ekonomi (JBE), 22(1), 25-33.

Hilmi, A. Z., \& Martani, D. (2012). Analisis FaktorFaktor Yang Mempengaruhi Tingkat Pengungkapan Laporan Keuangan Pemerintah Provinsi. Jurnal Simposium Nasional Akuntansi, 15(1), 61-65.

Khasanah, N. L., \& Rahardjo, S. N. (2014). Pengaruh Karakteristik, Kompleksitas, dan Temuan Audit terhadap Tingkat Pengungkapan Laporan Keuangan Pemerintah Daerah. Diponegoro Journal of Accounting, 3(3), 1-11.

Lesmana, S. I., \& Suhardjanto, D. (2010). Pengaruh Karakteristik Pemerintah Daerah terhadap Tingkat Pengungkapan Wajib Di Indonesia. Jurnal STIE Bank BPD Jateng, 6(2).

Martani, D., \& Liestiani, A. (2010). Disclosure Of Local Government Financial Statement In
Indonesia. Global Review of Accounting and Finance, 3(1).

Mustikarini, W. A., \& Fitriasari, D. (2012). Pengaruh Karakteristik Pemerintah Daerah Dan Temuan Audit Bpk Terhadap Kinerja Pemerintah Daerah Kabupaten/Kota Di Indonesia Tahun Anggaran

2007. Forum: Simposium Nasional Akuntansi, 1(1).

Pandansari, T. (2016). Tingkat Ketergantungan, Kompleksitas Pemerintah dan Tingkat Pengungkapan Laporan Keuangan Pemerintah Daerah. Jurnal Ekonomi Dan Bisnis, 19(3).

Rahayu, A., \& Mardiana, A. (2016). Pengaruh Karakteristik, Kompleksitas dan Temuan Audit terhadap Tingkat Pengungkapan Laporan Keuangan Pemerintah Daerah dengan Sistem Pengendalian Intern Sebagai Variabel Moderating pada LKPD Kabupaten/Kota di Sulawesi Selatan. Jurnal Ilmiah Akuntansi Peradaban, 1(1), 169-192.

Ratnasari, A. D. (2016). Pengaruh Karakteristik Pemerintah Daerah Dan Temuan Audit BPK RI Terhadap Tingkat Pengungkapan Wajib Laporan Keuangan Pemerintah Daerah (Studi Pada Pemerintah Provinsi Di Indonesia Periode 2012-

2014). Jurnal Fakultas Ekonomi Dan Bisnis, Universitas Muhammadiyah Yogyakarta, 1(1), $1-25$.

Republik Indonesia. (2004) Undang-Undang Nomor 32 Pasal 184 Tentang Pertanggungjawaban Pelaksanaan APBD.

Republik Indonesia. (2006) Peraturan Menteri Dalam Negeri Nomor 13 tentang Pedoman Pengelolaan Keuangan Daerah.

Sekaran, U., \& Bougie, R. (2017). Metode Penelitian untuk Bisnis (6th ed.). Jakarta: Salemba Empat.

Setyaningrum, D., \& Syafitri, F. (2012). Analisis Pengaruh Karakteristik Pemerintah Daerah Terhadap Tingkat Pengungkapan Laporan Keuangan. Jurnal Akuntansi \& Keuangan Indonesia, 9(2), 154-170.

Simbolon, H. A. U., \& Kurniawan, C. H. (2018). Pengaruh Karakteristik Pemerintah Daerah Terhadap Tingkat Pengungkapan Laporan Keuangan Di Seluruh Provinsi Indonesia. 
MODUS, 30(1), 54-70.

Sugiyono. (2015). Metode Penelitian Pendidikan

(Pendekatan Kuantitatif, Kualitatif dan $R \& D$ ).

Bandung: Alfabeta.

Winarna, J., \& Murni, S. (2007). Pengaruh Personal Background, Political Background Dan Pengetahuan Dewan Tentang Anggaran Terhadap Peran Dprd Dalam Pengawasan Keuangan Daerah

(Studi Kasus Di Karesidenan Surakarta Dan Daerah Istimewa Yogyakarta Tahun 2006). Jurnal Bisnis Dan Akuntansi, 9(2), 136-152. 